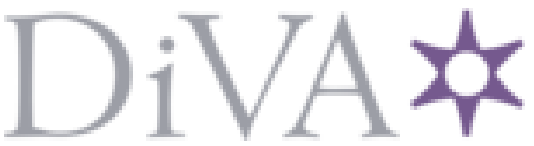

http://www.diva-portal.org

Preprint

This is the submitted version of a paper published in IEEE Transactions on Affective Computing.

Citation for the original published paper (version of record):

Sidorova, Y., Karlsson, S., Rosander, O., Berthier, M., Moreno-Torres, I. (2019)

Towards disorder-independent automatic assessment of emotional competence in neurological patients with a classical emotion recognition system: application in foreign accent syndrome

IEEE Transactions on Affective Computing

https://doi.org/10.1109/TAFFC.2019.2908365

Access to the published version may require subscription.

N.B. When citing this work, cite the original published paper.

Permanent link to this version:

http://urn.kb.se/resolve?urn=urn:nbn:se:bth-20310 


\title{
Towards disorder-independent automatic assessment of emotional competence in neurological patients with a classical emotion recognition system: application in foreign accent syndrome
}

\author{
Julia Sidorova, Member, IEEE, Simon Karlsson, Oliver Rosander, Marcelo L. Berthier, Ignacio Moreno-Torres
}

julia.a.sidorova@gmail.com

\begin{abstract}
Emotive speech is a non-invasive and costeffective biomarker in a wide spectrum of neurological disorders with computational systems built to automate the diagnosis. In order to explore the possibilities for the automation of a routine speech analysis in the presence of hard to learn pathology patterns, we propose a framework to assess the level of competence in paralinguistic communication. Initially, the assessment relies on a perceptual experiment completed by human listeners, and a model called the Aggregated Ear has been proposed that draws a conclusion about the level of competence demonstrated by the patient. Then, the automation of the Aggregated Ear has been undertaken and resulted in a computational model that summarizes the portfolio of speech evidence on the patient. The summarizing system has a classical emotion recognition system as its central component. The code and the data are available from the corresponding author on request.
\end{abstract}

Index Terms - biomarker, computational paralinguistics, emotion recognition, health care, foreign accent syndrome.

\section{INTRODUCTION}

Many complex and coordinated cognitive processes happen in the brain, when speech is produced, and when emotions come into play, such processes become even more complicated. Lesions in the brain getting in the way of the speech program can cause failures in the production of emotive speech at prosodic or segmental levels. The former is a wrong intonation that sends an unintended message and the latter is perceived as a foreign accent. Emotion plays a central role in communication, and consequently, an impaired ability for emotional speech has a devastating impact on the patients' personal lives and the capacity to carry out their professional activities. Regaining competences in communicating emotions is a desired result per se, whether as a consequence of recovery or compensatory skill acquisition (i.e. relearning the lost skills). In many disorders, emotive speech is sensitive to disease progression and recovery. In other words, it is a good candidate biomarker to be included into the panel of others that are taken into account. Formally speaking, a biomarker is "a characteristic that is objectively measured and evaluated as an indicator of normal biological processes, pathogenic processes, or pharmacologic responses to a therapeutic intervention" [1]. A speech-based biomarker takes speech as an input and evaluates the patient's speech production (quality, competence or other aspects) at either a particular time moment or as a trend during months of rehabilitation. Despite the fact that biomarkers based on emotive speech were proposed for a number of diseases, for example, stroke [2], Alzheimer's disease [3], autism spectrum disorder [4], mildly cognitive impairment [5], they are only making it to become one of the core diagnostic criteria. Their advantage over other biomarkers such as MRI, PET or lumbar punctures is that they are instantaneous to obtain, cost-effective and nonintrusive. The absence of expressive prosody in diagnostic criteria and instruments is primarily due to the difficulties in its reliable assessment [4], [7], namely, the paucity of reference standards, hearing and cognitive defects on the listener's side, altered emotional state of the listener, speaker's nonstandard dialect, and differences between genders, ages and social classes.

When the work concerns the clarity/correctness of emotive communications for a closed set of crisply defined emotional states (e.g. the basic emotions), the ground truth is typically derived via averaging naïve listeners' assessments to label the emotion (for example, anger), and then it is often further detailed with a probabilistic adverb. For example, in [4] the "Listener's Scores" were obtained as the averages of the ratings by six listeners without taking into account the intended emotions. Additionally, the listeners were asked to quantify how sure they were about their answers: "possibly", "probably", or "certainly". Our idea and the first contribution is to formalize such intuitive heuristic approaches to labeling emotional data in a fuzzy logic framework. We have applied the methodology for the assessment of competence based on the portfolio of evidence in educational research [9]. In our case, the 
emotional phrases and the accuracy of their recognition by the naïve listeners become the portfolio of evidence. The resulting framework is called the Aggregated Ear. We have completed perceptual experiments on a corpus with speech by the two patients, who were diagnosed with a neurological disorder (the Foreign Accent Syndrome) that manifests itself in a newly acquired accent and a partial or complete inability to communicate emotions. The success of every individual attempt has been estimated relying on the opinions of human judges, and approximating to which degree (on the scale from 0 to 1 ) the phrase succeeded to communicate the intended emotion. The individual successes are averaged into the score for the whole portfolio and approximate the speaker's competence in emotive communication. Then, the competence continuum is binned into the four disjoint intervals: excellent, when the speaker manages to convey the intended emotion on most occasions; improvable, when the speaker succeeds in more than half of cases; low, when the speaker fails in more than half of cases; and anti-knowledge competence resulting in frequency of successes below random.

As a second contribution, in order to assist (and ideally automate) the work of human judges/phoneticians at hospital, the possibilities of a pathology-independent approach has been explored and a summarizing model has been built that can distinguish among excellent emotive skills, anti-knowledge and insufficient skills. The summarizing model has a classical predictive model for emotion recognition from voice as a central component.

As far as biomarkers are concerned, there is big bulk of literature describing computational biomarkers that work on emotive speech: for stress recognition [11], [12], [13], for autism spectrum [15], [16], [17], for physical load [14], for Parkinson's Disease [18], [19], [6], [20], for Alzheimer's Disease [21], and intoxication [22], [15], [23], [24]. To our best knowledge, all of them use pathological data at a training stage. Certainly, the use of a system built for a particular disorder with well understood acoustic patterns is preferable, whenever possible. This is not applicable to our problem formulation, since our pathological data are scarce and, more importantly, we do not assume that the patterns of pathology manifestation in speech can be generalized. We assume (in line with what the medical literature affirms) that the neurological disorder in question affects the emotive speech "heterogeneously", i.e. without forming consistent patterns across the patients. Such a formulation is also useful for a "new" disorder, which is also the case for the Foreign Accent Syndrome.

The rest of the paper is organized as follows. Section 2 provides a description of the corpora, the auditory experiments to label the clinical corpus, and the final data set. Section 3 contains a brief background on fuzzy logic theory, explains the principles of the design of the Aggregated Ear together with the calculation of speaker's competence level based on the portfolio of evidence. In Section 4 the classical design of an emotion recognizer is reviewed, and, in order to make it a suitable piece of a summarizing model, an error measure is proposed.
Section 5 covers experimental work and gives a formal account regarding the correctness of the summarizing approach. Finally, in Section 6 the discussion is held and in Section 7 the conclusions are drawn.

\section{DATA}

This study is monolingual and is done for the Spanish language and deals with acted voice emotion, because this is the type of speech material used in neurological tests [25]. There are three types of speech corpora used in this study: 1) emotive communications by professional actors from the Interface database [26], 2) acted emotional speech by the two patients diagnosed with a rare and not well understood neurological disorder called the Foreign Accent Syndrome (FAS) at five time moments with months of therapeutic work between them, and 3) the speech by healthy control subjects, who are not actors, but were not trained to cope with the task conscientiously the way the patients were. The corpora with the speech by the patients and controls contain matching emotions (anger, sadness, happiness and the neutral state) and matching phrases. The corpus of actor speech has the same set of emotions.

Acted emotions by professional actors were recorded in silent rooms using high quality condenser microphones (AKG 320). The speakers read the sentences either from a prompt sheet or from the display of the PC. We have excluded the three emotions that are not contained in the clinical corpus. The resulting dataset contains 3846 speech samples: 725 anger, 732 happiness, 731 sadness, and 1658 neutral ones. (Although the exact percent correct for auditory evaluations was not reported for the Interface corpus, it has been used on multiple occasions in automatic emotion recognition and emotional speech synthesis in Spanish, e.g. according to [41] the corpus "was validated on the basis of the subjective tests whose results were considered sufficient to guarantee the expressiveness of the recordings". Should the corpus contain insufficient quality of emotional speech, the validity threat for the present study would be that the resulting predictive model is low performing in cross-corpus testing, which is not the case, as will be demonstrated in Section V.)

Prior to recording the clinical corpus with acted emotions, two patients (male and female) and two control subjects (male and female) signed an informed consent for participation after receiving an explanation of the aims and methodology of the study according to the Declaration of Helsinki. The study protocol was approved by the Ethical Committee of Malaga University. The material was audiotaped for later analysis using a FOSLEX-LE2 recorder and an Audiotechnica AT2035 microphone. The recording took place in a silent room. Acted emotional speech by each patient diagnosed with FAS was recorded at an initial state and at four time points after each consecutive therapeutic intervention. The therapies consisted in different actions: receiving pharmaceutical therapy, massive sentence repetition training to build synaptic connections around the lesion and create a new neuronal program, and other. For a 
complete description of each individual therapy and its expected neurological effect the reader is referred to [25]. For each recording session, the patients read aloud the prompted phrases that are listed in Table I with an instruction to convey a specific emotion resulting in 40 samples per treatment phase, and an overall of 400 samples in the entire dataset plus additional 80 data points by controls.

TABLE I

TEN SENTENCES USED AS PROMPTS WHILE RECORDING THE CLINICAL DATA

\begin{tabular}{|c|c|}
\hline The phrase & Translation \\
\hline Hoy nos vamos al campo. & Today we go to the fields. \\
\hline $\begin{array}{l}\text { Maria se ha llevado tu } \\
\text { boligrafo. }\end{array}$ & Maria has taken your pen. \\
\hline $\begin{array}{l}\text { En tu casa hay un perro } \\
\text { enorme. }\end{array}$ & $\begin{array}{l}\text { There is a huge dog at your } \\
\text { house. }\end{array}$ \\
\hline $\begin{array}{l}\text { Manana comemos en casa } \\
\text { del abuelo. }\end{array}$ & $\begin{array}{l}\text { Tomorrow we are eating at } \\
\text { grandfather' house. }\end{array}$ \\
\hline $\begin{array}{l}\text { Se ha tomado toda la } \\
\text { comida. }\end{array}$ & He has eaten all the food. \\
\hline Hoy esta lloviendo mucho. & Today it is raining heavily. \\
\hline Hoy hace mucho calor. & Today it is very hot. \\
\hline $\begin{array}{l}\text { El jefe no ha preguntado } \\
\text { por ti. } \\
\text { Mi hija quiere casarse en } \\
\text { Italia. }\end{array}$ & $\begin{array}{l}\text { The boss has not asked } \\
\text { about you. } \\
\text { My daughter wants to get } \\
\text { married in Italy. }\end{array}$ \\
\hline $\begin{array}{l}\text { Vamos a visitar a los } \\
\text { primos del campo. }\end{array}$ & $\begin{array}{l}\text { We will visit out cousins in } \\
\text { the village. }\end{array}$ \\
\hline
\end{tabular}

\section{A. Perceptual Experiment to Label the Clinical Corpus}

Twenty five listeners agreed to participate in labeling the clinical data. All of them were native or fluent Spanish speakers, who were aware of the purpose of the study, but did not have the knowledge about the medical status of the speakers nor the intended emotion. Depending on their availability, they all labeled different number of phrases: the mean number of phrases to label is 185 with the standard deviation of 125 . Overall 5030 evaluations have been done for the clinical corpus, with each phrase being evaluated around ten times but never twice by the same listener. The regional spectrum of the listeners is as follows: bilingual Spanish-Catalan 37\%, monolingual Spanish 27\%, Argentine 8\%, Peru 7\%, Chile 1,5\%, Colombian 2\%, and fluent foreign Spanish speakers: Brazilian 1\%, Russian 11\%, and Serbian 5,5\%. Other demographic characteristics of the Aggregated Ear are: its mean of age is 42,8 years $(\mathrm{sd}=14.42)$, and the gender composition is $70 \%$ male and $30 \%$ female. The phrases were retrieved at random and played to the listener once, who was asked to choose which of the four emotions the phrase transmits: anger, sadness, happiness, or the neutral state via either pressing a corresponding button on the key board or saying it aloud. The evaluator had an option to skip a particular data point, if it was not clearly heard. Also, typically in the beginning of the experiment, the judges were asking to repeat the stimulus or had questions. This produced the inexactness in the number of evaluations: 5030 for 480 samples. The report describing the perceptual experiment has the following fields: time stamp, an anonymized ID of the speaker or control subject, a treatment phase for the patients or the word "control", an anonymized ID of the listener, listener's age, listener's sex, listener's linguistic background, the intended emotion, and the perceived emotion.

While doing a pre-experiment, the problem became clear that some phrases were perceived to have an unintended emotional quality such as "emphatic" or "surprise", but could not, from the point of view of the listeners, be attributed to any of the four intended emotions. In such cases, it was decided to choose the neutral state. Whenever the listener reported being unsure which of the two emotions was perceived, the instruction was given to take a more confident option. In general, the majority of the listeners affirmed that the patients were foreign speakers, and that their speech is perceived as strangely sounding and is on most occasions hard to interpret from an emotional point of view. The cognitive load of the evaluators was high, and, in our opinion, it would not had been feasible to add a scale of confidence, and instead we approximate it, as will be explained in Section 3.

\section{B. Data Set}

Once the perceptual experiment had been completed, a problem emerged: the percent correct achieved by the patients were rather low, and therefore, no portfolios with successful emotional communications were available. The results of the perceptual experiment are summarized as the plot boxes for male and female patients in Figure 1 and 2, respectively. To be able to test the summarizing models on qualitatively distinct competences in emotional communication, we have grouped the samples into four bins according to the frequency of successful recognitions by the humans.

Excellent (Bin 4) includes 99 phrases with the values in the interval [0.75-1], which characterizes the phrases of excellent clarity. Databases with emotional speech by professional actors fall into this bin. The rate of $75 \%$ in auditory evaluations is the average between the strict and permissive criteria on the clarity of acted emotion in the literature, e.g. in Berlin database only the phrases with $>80 \%$ of correct recognition by humans were kept as quality data points, while only $69 \%$ were reported for a corpus with Danish speech [27]. On average, the emotional speech by the patients and controls from this competence bin is as clear as speech from a database by professional actors, thus, making $75 \%$ a sufficient target quality. The distribution of emotions is: 4 for anger, 38 for happiness, 36 for sadness, and 21 for the neutral state. 


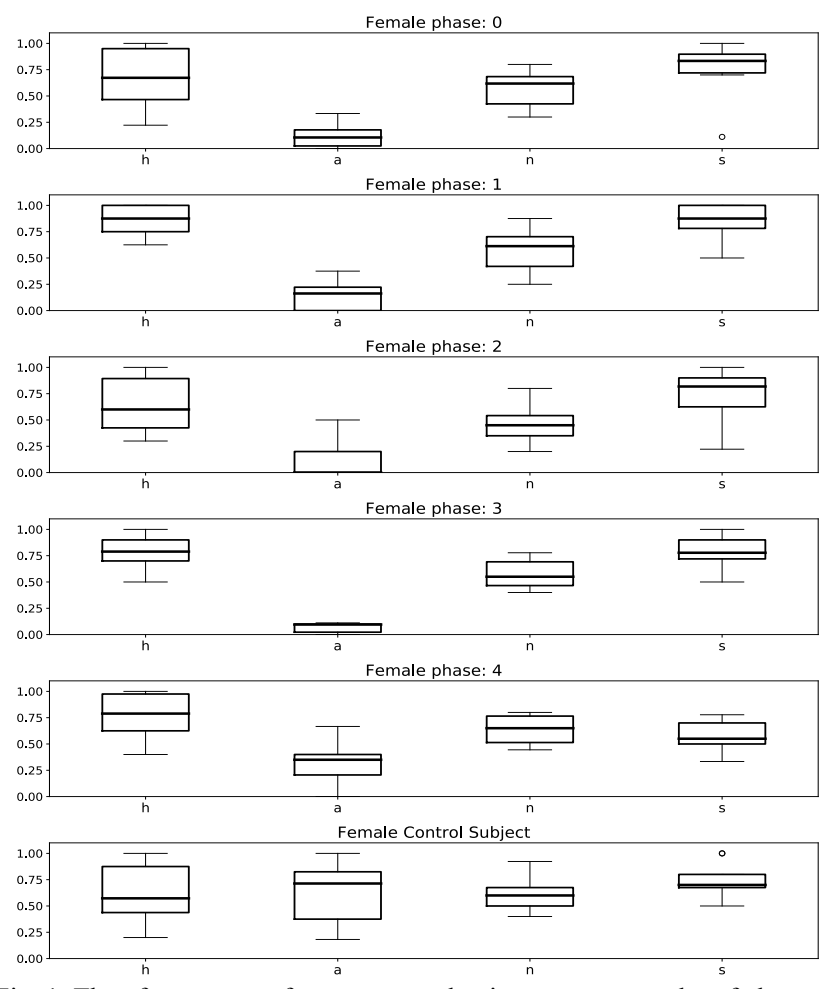

Fig. 1. The frequency of correct evaluations as a result of human evaluations for the female patient and the female control subject.

Improvable (Bin 3) includes 131 phrases with the values in the interval $[0,5-0,75)$ with rather successful than unsuccessful attempts, i.e. those, which are correctly perceived in more than half of cases and yet not as successful as the ones from Bin 4. The distribution of emotions is: 14 for anger, 32 for happiness, 30 for sadness, and 55 for the neutral state.

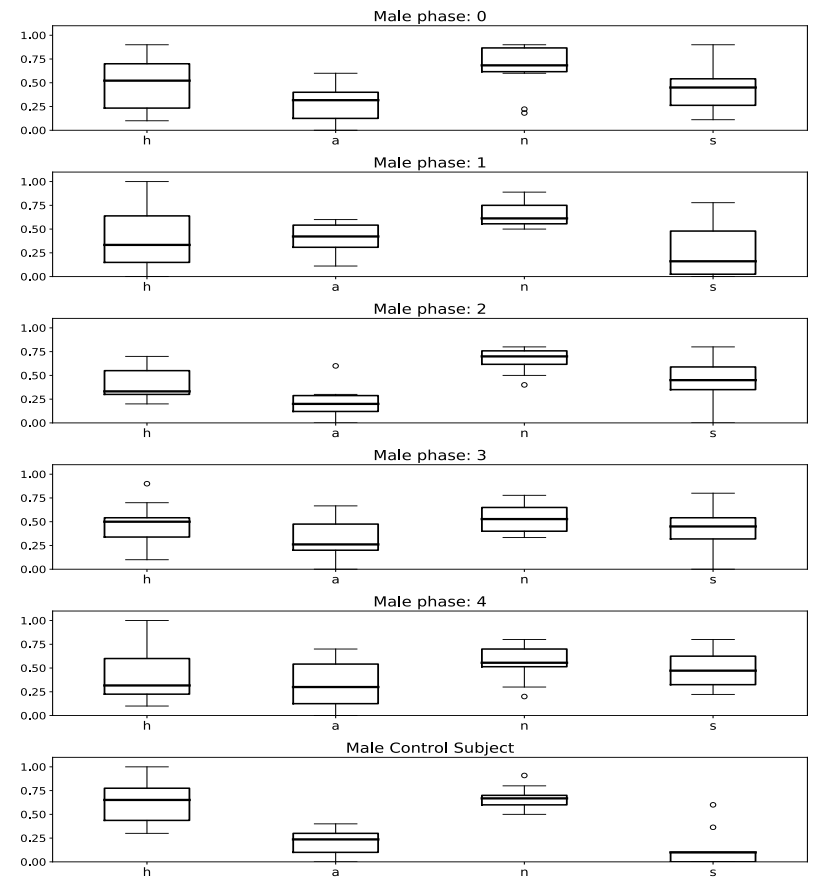

Fig. 2. The frequency of correct evaluations as a result of human evaluations for the male patient and the male control subject.
Low Competence (Bin 2) includes 134 phrases with the values in the interval [0.25-0.5) with largely unsuccessful emotive communications, which are misinterpreted by the listeners in more than half of cases. The distribution of emotions is: 31 anger, 30 happiness, 34 sadness, and 39 for the neutral state.

Anti-knowledge (Bin 1) includes 116 phrases with the values in the interval [0-0.25) with the frequency of successes below the chance level. A (degraded) generative model is required to perform below random or a will to do badly on the test, see Appendix. The distribution of emotions is: 69 anger, 19 happiness, 5 normal, and 23 sadness.

\section{ASSESSMENT OF SPEAKER's COMPETENCE}

In order to assess the patient's ability to communicate voice emotion, a mapping is needed from at times contradictory evaluations by human judges into speaker's competence bin: excellent skills in emotional communication, improvable skills, low competence, and anti-knowledge. Approaches based on fuzzy logic can summarize data into a qualitative conclusion [28], and, following this idea a summary is created about patient's competence from the portfolio of evidence.

\section{A. Formal and Cognitive Background on Fuzzy Sets}

Fuzzy sets were initially designed to formally account for inherently relative assessments about subjective notions such as, for example, a tall man or a beautiful woman.

Definition [29]: A fuzzy set A in X is characterized by a membership function $\mathrm{f}_{\mathrm{A}}(\mathrm{x})$, which associates with each point in $X$ a real number in the interval $[0,1]$, with the value of $\mathrm{f}_{\mathrm{A}}(\mathrm{x})$ at $\mathrm{x}$ representing the "grade of membership" of $x$ in A. For the opposite quality the membership value is defined as: $\mathrm{f}_{\text {not } A}(\mathrm{x})=1-\mathrm{f}_{\mathrm{A}}(\mathrm{x})$.

Fuzzy membership scores reflect the varying degree, to which different cases belong to a set and combine a qualitative and quantitative assessment. A tangible event called an "anchor" must occur at the values of a state switch and such values are application-dependent. (For example, if percent correct on auditory tests is a membership value for the notion of being successfully communicated, then the values $0.75,0,5$ and 0.25 are anchors.) A fuzzy membership score of 1 indicates a full membership in a set; the scores close to 1 (e.g. 0.8 or 0.9 ) indicate strong but not quite full membership in a set; 0.5 is the point of maximal ambiguity regarding the quality; the scores greater than 0.5 but less than 0.8 indicate weaker but still notable class membership, scores less than 0.5 but greater than 0 (e.g. 0.2 and 0.3 ) indicate that the objects are more "out" than "in" a set, but still are weak members of the set; and finally a score of 0 indicates full non-membership in the set.

Beyond the formal work of Zadeh [29] and colleagues there are competing views on where fuzziness arises and there is a body of experimental cognitive research conducted, for example [30] is a review. Let us summarize 
the part, which is useful for the interpretation of the proposed construct called the Aggregated Ear. In the school of thought called the likelihood view the value 0.7 is assigned to the membership function, if $70 \%$ of the population declares that the sample belongs to the category. Under this model there are the following sources of fuzziness: errors in measurement, incomplete information, and interpersonal contradictions. These sources of fuzziness are present in the case of auditory evaluations of prosody, as they were named among the challenges of constructing prosody-based biomarkers in the Introduction. The advocates of the likelihood view adhere to the philosophical belief that meaning is essentially objective and is a convention among the users of the language, while its measurement is essentially a vague process. Within the similarity view (another school of thought), fuzziness arises from the insufficient cognitive abilities of the person, who is faced with the task of "comparing the object with a certain prototype or imaginable ideal". It arises naturally from prototype theory, where membership is a notion of being similar to a representative of the category. The membership function measures the degree of similarity of an element to the set in question. It is assumed that there exists a perfect example of the set (or the category) that belongs to the set to the full degree. Others belong to the set to a degree measured by their relative distance to the perfect sample. In [31], [32], it is claimed that in rating prototypicality of a stimulus, subjective probability is sufficient. We assume that the ideal representations of an emotion exist in the listeners' mind. We want the Aggregated Ear to map samples of emotional speech to their prototype (the intended emotion) via outputting a membership value in the sense of the similarity view point, which is approximated as frequency of correct evaluations by the human judges, as in the likelihood view.

\section{B. Procedure to Construct the Aggregated Ear}

The fuzzy logic based framework in portfolio assessment [9] was designed for cases, when the assessment involved several aspects of competence and an aggregated view of many assessors. The portfolio of evidence is understood as any relevant material. In the present study, the individual competences are the ones of communicating the four basic emotions at a paralinguistic level, there are around 10 judges per phrase, and the portfolio of evidence on the speaker contains the emotional phrases and their evaluations by the human judges. Let $\mathrm{E}$ be the matrix of evidence of size: 10 phrases $\times 4$ emotions for every patient at a particular time moment. The elements of matrix $\mathrm{E}$ $\mathrm{e}_{\mathrm{i}, \mathrm{j}}=\operatorname{count}(\mathrm{i}, \mathrm{j})$ with $\mathrm{i}=1, \ldots, 10$ enumerating the phrases and $\mathrm{j} \in\{\mathrm{a}, \mathrm{n}, \mathrm{s}, \mathrm{h}\}$ enumerating emotions, are calculated in the following way. Let the individual matrices of evidence for the individual emotions, -- anger, sadness, happiness, and neutral state, -- be stored as a correspondingly named matrix $\{\mathrm{A}, \mathrm{S}, \mathrm{H}, \mathrm{N}\}$ of size 10 phrases $\times \mathrm{n}$ listeners with elements guess $\mathrm{i}_{\mathrm{i}, \mathrm{k}}$. If listener $\mathrm{k}$ correctly identifies the intended emotion for phrase $i$, the value guess $_{\mathrm{i}, \mathrm{k}}=1$, otherwise guess $\mathrm{i}_{\mathrm{i}, \mathrm{k}}=0$. Therefore, $\operatorname{count}(\mathrm{i}, \mathrm{j})$ from matrix $\mathrm{E}$ is a row sum for matrices $\mathrm{A}, \mathrm{S}, \mathrm{H}$, and $\mathrm{N}$. The speaker's competence in communicating a particular emotion based on the evidence containing 10 attempts (from Table I) is set to competence (speaker, time moment $)=\Sigma_{v i, v j} \operatorname{count}(i, j) / 10$. Thus, the overall emotional competence is the average of competences in conveying individual emotions, where the competence is set to be equal to the ratio of successful attempts in communicating an intended emotion in the portfolio. In the above, it is implied that the four emotions are of equal importance. Finally, the interval of speaker's competence is binned into the qualitatively distinct levels of competence: Excellent with the values of the membership function in $[0.75,1]$, Improvable with the values of the membership function are $[0.5,0.75)$, Low for $[0.25,0.5)$, and Anti-knowledge for [0, 0.25).

\section{CANDidate PREDictive Models AND ERRoR MEASURE}

\section{A. Classical Emotion Recognizer}

A predictive model designed to recognise emotion from voice takes a sample of speech as an input and outputs the emotional class for it. Typically, its architecture is based on the supervised machine learning approach [33], [34], [35]. There are variations in the classical design with respect to preprocessing, features, and a classification function.

Step 0: Preprocessing options. 1) The Z-normalisation, i.e. all the features are set to mean 0 and sd 1, gives good results in cross-corpus emotion recognition [10], and its purpose is to achieve speaker normalisation. 2) Since the Interface corpus contains diverse type of material, from syllables to passages of text, a duration-based filtering has been considered, under which the phrases from the actor corpus were filtered out, if they were outside of the duration range in the clinical corpus.

Step 1: Feature Extraction. Two state of the art acoustic feature sets have been extracted from the speech signal: the genereric set with 990 features (emobase) and the large one with 6555 features (emo_large) with open-source software openSMILES [36], [37].

Step 2: Classification. Since there are many features, we have done a feature selection step, which implements correlation based feature subset selection [38] (BestFirst\&CfsSubsetEval in weka). For classification function we have considered C4.5, Random Forest, the Support Vector Machine and the Multilayer Perceptron in the weka implementation [39].

Our idea is to benefit from the fact that a good predictive model will classify the correctly expressed emotive samples with a high confidence, the slightly corrupted ones may still be classified correctly, possibly with a lower confidence, and as for the corrupted part of the clinical data set, we expect it to be misclassified on most 
occasions. Additionally, we wish the error patterns of the computational model to be close to the ones of human evaluations. Therefore, among equally well performing candidate models the one is preferred, which is characterized with the least value of the proposed error, the aim of which is to penalize divergence, qualitative and quantitative, between the conclusions by the Aggregated Ear and by the computational summarizing model. (The candidate predictive models are trained on actors' speech, and the test samples that are patients' speech do not contribute to parameter estimation for the candidate models. The training/testing protocol of the experiment is depicted in Figure 3.)

\section{B. Error Measure}

Once a speech sample has been mapped into a recognition class, the answers by a predictive model are compared to the answers from human evaluations, and, if they agree (for example, the classifier's probability is 0.8 for anger and the Aggregated Ear concluded that the sample communicates anger with 0.8 value of the membership function), then it is a full classification success. Otherwise, the error is quantified as follows. There are three types of unwanted disrepancies between the automatic method and the human evaluations, and they are of different degrees of graveness. In the worst case the automatic model outputs a wrong competence level about the portfolio of evidence. A less grave error is when, although the global conclusion about the portfolio of evidence is the same, at the level of individual data points the automatic model is characterised with a different distribution across the bins compared to the distribution of the binned values of the membership function. (The bins were defined in Section II.B) Finally, the least grave error is numeric deviations of continuous values between classifier's probabilities and the membership function. The above can be expressed with:

Error(model, evidence $)=\mathrm{I}_{1} \Delta_{\text {competence }}+\mathrm{I}_{2} \mathrm{~d}_{\mathrm{uOLS}}+\mathrm{I}_{3} \mathrm{~d}_{\mathrm{KS}}(4.1)$

where

- $\Delta_{\text {competence }}$ is the ordinary least squares (OLS), that is, a sum of squared differences of the conclusions about the competence bin for the available portfolios of evidence. For example, if the computational model summarises four portfolios of evidence into the following competence levels defined by their bin numbers $\{1,1,4,3\}$ and human evaluations putt hem into bins $\{2,1,4,4\}$, then $\Delta_{\text {competence }}=(1-2)^{2}+(1-1)^{2}+(4-4)^{2}+(3-4)^{2}$;
- $\mathrm{d}_{\mathrm{uOLS}}$ is a distance equal to unweighted OLS (unweighted in the sense that, in order to make the OLS invariant with respect to an unballanced distribution of data points among the competence bins, a denominator $\mathrm{k}_{\mathrm{c}}$ is added, which is the number of data points in the competence bin c). The compared distributions are the binned classifier's probabilities to the intended emotion $(\mathrm{X})$ and the binned values of the membership function:

$$
\mathrm{d}_{\mathrm{uOLS}}=\sum_{\mathrm{c} \text { in }\{1,2,3,4\}} \sum_{\mathrm{i}=1 . . \mathrm{kc}}\left(\mathrm{x}_{\mathrm{i}}-\mathrm{c}_{\mathrm{i}}\right)^{2} / \mathrm{k}_{\mathrm{c}} ;
$$

- $\mathrm{d}_{\mathrm{KS}}$ is a statistical distance [42], the value of which comes from the Kolmogorov-Smirnov (KS) test, in which the continuous values of the classifier's probability and the membership function are compared. The KS test determines if the samples are drawn from the same underlying continuous population characterised by cumulaive distributions $\mathrm{F}(\mathrm{X})$ and $\mathrm{F}(\mathrm{Y})$. The distance between these two populations is defined by the KS test in the form

$$
\mathrm{d}_{\mathrm{KS}}=\max \left|\mathrm{F}\left(\mathrm{x}_{\mathrm{i}}\right)-\mathrm{F}\left(\mathrm{y}_{\mathrm{i}}\right)\right|
$$

- I is a vector of indicator variables:

$\mathrm{I}_{1}=1$, if the models suggest different competence bins, and $\mathrm{I}_{1}=0$ otherwise.

$\mathrm{I}_{2}=0$, if $\mathrm{I}_{1}=1$ (a higher order of error overtakes, and the lower errors are held irrelevant), else $I_{2}=0$, if the compared models output equal values, and $\mathrm{I}_{2}=1$ otherwise.

$\mathrm{I}_{3}=0$, if $\mathrm{I}_{1}=1$ or $\mathrm{I}_{2}=1$, else $\mathrm{I}_{3}=0$, if the compared models output equal values, and $\mathrm{I}_{3}=1$, otherwise.

The best model is the one that is characterised with the smallest error from Equation 4.1:

$$
\begin{aligned}
& \text { model }=\operatorname{argmin}_{\text {models }\{1, . ., \mathrm{n}\}}\left\{\text { Error}_{\left(\text {model }_{1}, \text { evidence }, \ldots,\right.},\right. \\
& \text { Error }\left(\text { model }_{\mathrm{n}}, \text { evidence }\right\} .
\end{aligned}
$$

As is expressed via the indicator vector $\mathbf{I}$, the highest level of the error determines which model is chosen, and this level is detailed down (through binned to continuous resolution), as long as the models are equally well performing and weaker models are discarded. At the time of performance comparison, confidence margins are taken into account, i.e. value 1 - value 2 is taken to be 0 , if the interval defined by value $1-$ value $2 \pm$ confidence margin includes 0 . 


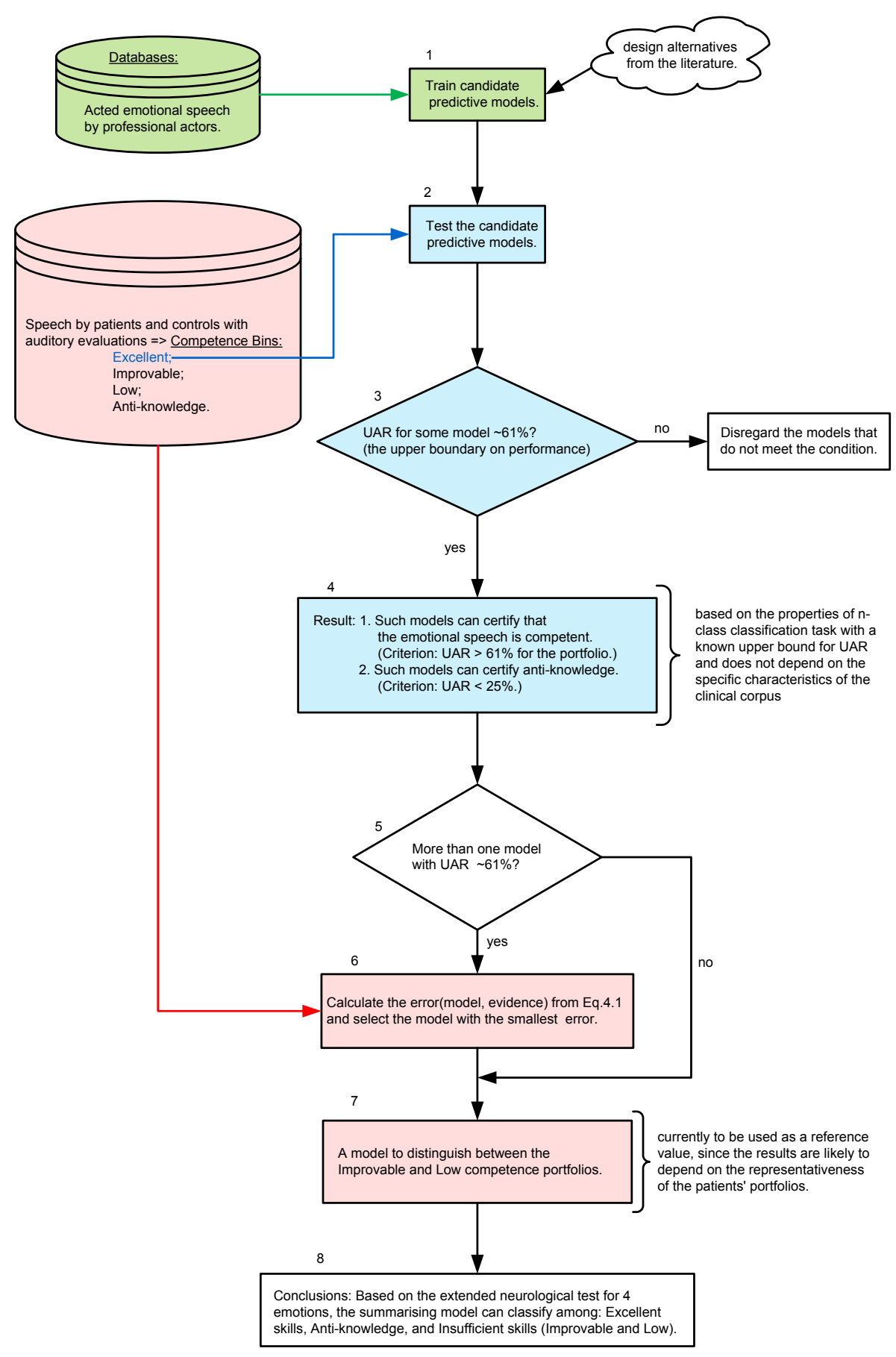

Fig. 3. The training/testing protocol of the study.

\section{Summarizing Model}

The summarizing model receives speech of the patient (portfolio) as an input and as an output it gives speaker's competence bin. In the literature, as classes are often unballanced, the standard for cross-corpus evaluation of a classical emotion recognizer is UAR, which is the accuracy per class divided by the number of classes without considering the number of instances in them. The classical emotion recognizer is the main component of the summarizing model (as depicted in Figure 4), and it uses the UAR by the emotion recognizer to get a competence bin in the following way.

We claim that the Excellent skills for emotional communication can be confirmed with the UAR equal to the highest reported value, i.e. the upper bound for a 4-class emotion recognition with a classical recognizer. The literature suggests the following baselines: for the Danish Emotional Speech database 25-43\% UAR was obtained and $45-62 \%$ for the Berlin database, see Figure 5. 


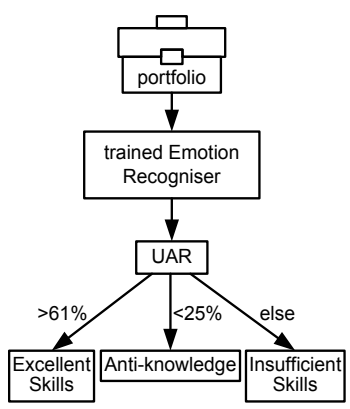

Fig. 4. The architecture of a summarizing model.

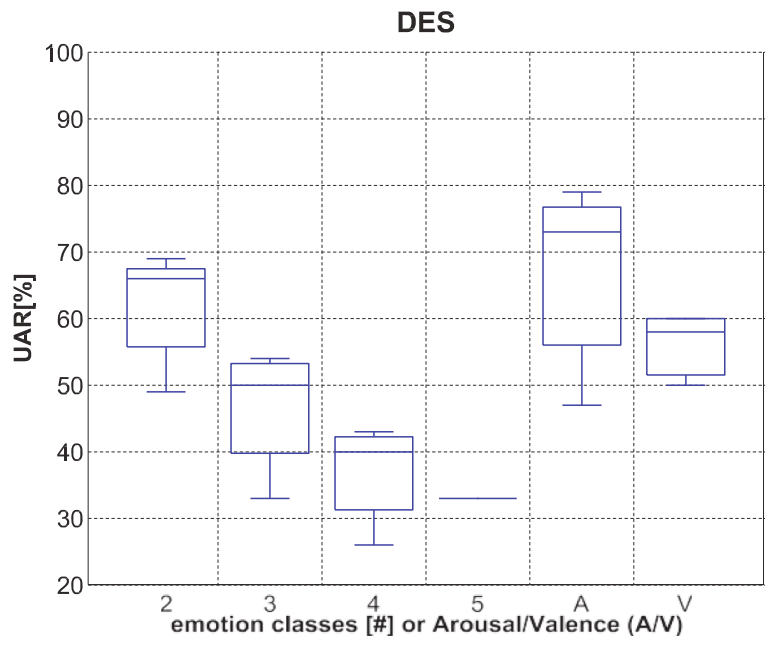

EMO-DB

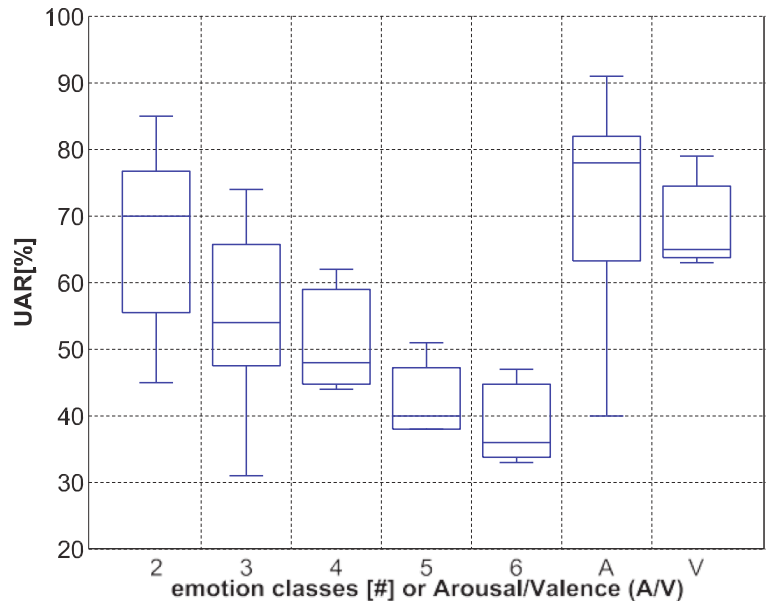

Fig. 5: Box-plots for unweighted average recall (UAR) in \% for cross-corpora testing on the corpora with acted emotional speech (DES and EMO-DB corpora). Results obtained by varying the number of classes (2-6) [10].

The formal account regarding the correctness of this claim is Lemma 3 in Appendix: "When patterns degrade, recognition accuracy goes down below 61\%".

We claim that the anti-knowledge level of competence can be confirmed via the use of a classical emotion recognizer, if the UAR is below the chance level ( $25 \%$ for a 4-class recognition task). The corresponding Lemma 4 in
Appendix is: "Knowledge about patterns in the generative model (i.e. in the speaker) is required for the recognition model to output the value of the UAR below random".

The insufficient skills (Low and Improvable) can be certified via excluding the Excellent and Anti-knowledge competences. Seemingly, the final refinement of the decision between Improvable and Low cannot be made without a data-driven approach.

To sum up, as a consequence of knowing the upper bound on the performance metric (UAR) and the properties of the recognition on a balanced set for a 4-class problem, three levels of competence can be certified with the summarizing model: Excellent, Insufficient (Improvable or Low), and Anti-knowledge. In Section 5 we will make some advances towards learning a decision boundary between Improvable and Low and outline the plan for its approximation in the Future Work.

\section{EXPERIMENTS}

\section{A. Training}

The candidate models have been trained on the Spanish part of the Interface corpus with acted emotional speech containing four emotions. This stage of the experiment corresponds to Block 1 in Figure 3.

\section{B. Cross-corpus testing}

By the experimental design (since $75 \%$ of listeners recognised the intended emotion), Bin 4 of the clinical corpus is free of pathological distortions that would hamper human understanding at a paralinguistic level. The unweighted average recall (UAR) on the Excellent set is a measure for model's strength in the emotion recognition mode. One of the candidate models (the SVM with duration-based filtering) managed $61 \%$ UAR, which is at the upper boundary of the levels reported for cross-corpus emotion recognition for four emotional classes for acted emotional speech using the same set of features. This stage of the experiment corresponds to Block 2 in Figure 3.

\section{Summarizing the portfolio of evidence}

From the input with the partially distorted samples in the clinical data set we expect the model to recognize the more correct ones, and the recognition accuracies to go down on the distorted samples. (Appendix provides a formal account of such expectations, i.e. Lemma 3.) The frequency of the correct recognition by the candidate predictive models is reported in Table II. Then, the frequency of correctly recognised samples is mapped into their competence bins, and the results are compared to the bins based on human evaluations (Table III). While identifying the bin by the predictive model, confidence margins have been taken into account and calculated according to

$$
\operatorname{error}_{\mathrm{S}}(\mathrm{h}) \pm \mathrm{z}_{\mathrm{n}}\left(\operatorname{error}_{\mathrm{S}}(\mathrm{h})\left(1-\operatorname{error}_{\mathrm{S}}(\mathrm{h})\right) / \mathrm{n}\right)^{1 / 2}
$$


where $z_{n}=1.96$, (for the confidence level of $95 \%$ ), error ${ }_{s}(h)$ is the sampling error for hypothesis $\mathrm{h}$ formulated in the form a predictive model, and $\mathrm{n}$ is the number of data points in the test set [40]. For the borderline evidence portfolios, for which the interval defined by the prediction and the margins overlaps with two adjacent competences (e.g. excellent/ improvable), the $\Delta_{\text {competence }}$ is set to 0 to both of the bins. From Table III it can be observed that two candidate models have managed to match the competence bins correctly: the SVM with a duration filter and the SVM without a duration filter.

TABLE II

FREQUENCY OF CORRECTLY RECOGNISED SAMPLES FOR DIFFERENT COMPETENCE LEVELS

\begin{tabular}{lcccc}
\hline \hline \multicolumn{1}{c}{ Method } & $\begin{array}{c}\text { Excellent } \\
\text { (Bin 4) }\end{array}$ & $\begin{array}{c}\text { Improvable } \\
\text { (Bin 3) }\end{array}$ & $\begin{array}{c}\text { Low } \\
\text { (Bin 2) }\end{array}$ & $\begin{array}{c}\text { Incompetent } \\
\text { (Bin 1) }\end{array}$ \\
\hline $\begin{array}{l}\text { Human } \\
\text { judgments }\end{array}$ & $\mathbf{0 . 7 5}$ & $\mathbf{I 0 . 5 - 0 . 7 5 )}$ & $\begin{array}{c}\text { [0.25- } \\
\mathbf{0 . 5}\end{array}$ & $\mathbf{5 0 . 2 5}$ \\
$\begin{array}{l}\text { MLP, duration } \\
\text { C4.5, duration }\end{array}$ & 0.53 & 0.36 & 0.28 & 0.31 \\
$\begin{array}{l}\text { Random Forest, } \\
\text { duration }\end{array}$ & 0.55 & 0.32 & 0.34 & 0.22 \\
$\begin{array}{l}\text { SVM, large } \\
\text { feature set, } \\
\text { duration }\end{array}$ & 0.37 & 0.48 & 0.34 & 0.12 \\
$\begin{array}{l}\text { SVM, duration } \\
\text { SVM }\end{array}$ & $\mathbf{0 . 6 7}$ & $\mathbf{0 . 4 4}$ & $\mathbf{0 . 3 1}$ & $\mathbf{0 . 1 8}$ \\
$\begin{array}{l}\text { SVM, z-norm, } \\
\text { duration }\end{array}$ & 0.47 & 0.56 & 0.49 & 0.31 \\
\hline \hline
\end{tabular}

TABLE III

THE $\Delta_{\text {COMPETENCE }}$ ERROR COMPONENT FOR DIFFERENT COMPETENCE LEVELS.

\begin{tabular}{|c|c|c|c|c|c|}
\hline Model & Excellent & Improv. & Low & Incompetent & $\Delta_{\text {COMPETENCE }}$ \\
\hline $\begin{array}{l}\text { Human } \\
\text { judgments }\end{array}$ & $\mathbf{0}$ & $\mathbf{0}$ & $\mathbf{0}$ & $\mathbf{0}$ & $\mathbf{0}$ \\
\hline MLP, duration & -1 & -1 & 0 & 0 & 2 \\
\hline $\begin{array}{l}\text { C4.5, duration } \\
\text { Random }\end{array}$ & -1 & -1 & 0 & 0 & 2 \\
\hline $\begin{array}{l}\text { Forest, } \\
\text { duration }\end{array}$ & -1 & 0 & 0 & 0 & 1 \\
\hline $\begin{array}{l}\text { SVM, large } \\
\text { feature set, } \\
\text { duration }\end{array}$ & -1 & -1 & 0 & 0 & 2 \\
\hline $\begin{array}{l}\text { SVM, } \\
\text { duration }\end{array}$ & $\mathbf{0}$ & $\mathbf{0}$ & $\mathbf{0}$ & $\mathbf{0}$ & $\mathbf{0}$ \\
\hline SVM & $\mathbf{0}$ & $\mathbf{0}$ & $\mathbf{0}$ & $\mathbf{0}$ & $\mathbf{0}$ \\
\hline $\begin{array}{l}\text { SVM, z-norm, } \\
\text { duration }\end{array}$ & 1 & 0 & 0 & 0 & 1 \\
\hline
\end{tabular}

\section{Finding the model with smallest error}

From Table III, there are two equally well performing models (for which the first error component from Equation 4.1 $\Delta_{\text {competence }}=0$, and which also have insignificantly different UARs on the Excellent set: 0.6 and 0.61). They are the SVM without Z-normalisation with and without duration-based filtering. Until now, for the calculation of $\Delta_{\text {competence }}$ the classification has been made into a discrete set of emotions, while for the calculation of the other two error components ( $d_{\mathrm{uOLS}}$ and $\mathrm{d}_{\mathrm{KS}}$ ), a probability is required to be associated to a prediction. Different classifiers have different ways of associating probability to the prediction, in the case of the SVM calibration models are fit to the outputs of the support vector machine, and the predicted probabilities are coupled [8]. The $d_{\text {uots }}$ compare the distributions of the binned values of the membership function and the classifier's probabilities. The smaller values of the $d_{\text {uots }}$ talk in favour of the bigger resemblance of the compared distributions. For the full model $d_{\text {uols }}$ is $9.05 \pm 0.25$, and $\mathrm{d}_{\text {uots }}$ for a model with duration control is $9.36 \pm 0.26$, which makes us to conclude that the models are insignificantly different with respect to $d_{\text {uols. }}$. Therefore, following the definition of the error measure from Section IV.B, the third numeric component of the error from Equation 4.1 is considered: the KS distance $d_{K S}$ is 0.4 and 0.42 for the duration control and the full model, respectively. The model with duration-based filtering is characterised with the smallest error and, therefore, is the preferred one. This stage of the experiment corresponds to Block 6 in Figure 3. In the future, the boundary between Improvable and Low will be approximated with this model.

\section{E. Matching competence bins of human evaluations to the competence bins by the summarising model}

Experimentally obtained computational counterparts of the competence bins are presented in Table IV. They are defined by the frequency of correct automatic recognition for the four classes in the portfolio and take into account the confidence interval.

TABLE IV

THE COMPETENCE BINS OF HUMAN EVALUATIONS AND THE COMPUTATIONAL MODEL

\begin{tabular}{lcc}
\hline \multicolumn{1}{c}{ Competence Bin } & Humans & Automatic Recognition \\
\hline Excellent & {$[0.75 ; 1]$} & {$[0.58 ; 0,76]$} \\
Improvable & {$[0,5 ; 0,75)$} & {$[0.36 ; 0,53]$} \\
Low & {$[0,25 ; 0,5)$} & {$[0,23 ; 0,39]$} \\
Anti-knowledge & {$[0 ; 0,25)$} & {$[0,11 ; 0,25]$} \\
\hline
\end{tabular}

For the computational model the point of maximal ambiguity concerning the quality of being competent, which corresponds to the membership function $\mathrm{f}_{\text {competent }}$ (portfolio) equal to 0.5 , is the intersection of the low and improvable competence bins: [0.36-0.39]. For the moment we only state that this correspondence is specific to the database. 


\section{F. Summaries of individual portfolios}

For data exploration purposes, once the best model has been decided on (and there are no other pending decisions to be made), let us run the candidate models in the mono-speaker mode to see, whether the model choice made us overlook a successful model under the mono-speaker way of evaluation. The "portfolio summary" has been done in the mono-speaker way for the two patients. Tables V, VII (frequecies of correctly recognised data points) and VI, VIII ( $\Delta_{\text {competence }}$ calculated) represent the results on the competence detection for the two neurological patients at five different time moments separated with months of treatment. In only one out of ten evaluations (female patient, phase 0) the discarded model that implements the SVM with the z-normalisation filter has a better $\Delta_{\text {competence }}$ error component over the chosen model, and, therefore, no significantly better model has been overlooked. As could have been expected, the machine recognition has given a pessimistically biased assessment of the speaker's competence, because cross-corpus emotion recognition is a hard task: for the excellent portfolio with a balanced distribution of emotional classes $>0.75$ by humans corresponds to only 0.61 by the machine. But given that the number of data points is 40 at a time moment in a neurological check up, this has been "rectified" with a wide confidence margin of around 0.1 .

TABLE V

FREQUENCY OF CORRECTLY RECOGNISED SAMPLES FOR THE FEMALE PATIENT

\begin{tabular}{lccccc}
\hline \multicolumn{1}{c}{ Model } & Phase 0 & Phase 1 & Phase 2 & Phase 3 & Phase 4 \\
\hline $\begin{array}{l}\text { Human } \\
\text { judgments }\end{array}$ & $\mathbf{0 . 5 3}$ & $\mathbf{0 . 5 9}$ & $\mathbf{0 . 4 8}$ & $\mathbf{0 . 5 5}$ & $\mathbf{0 . 5 7}$ \\
$\begin{array}{l}\text { MLP, duration } \\
\text { C4.5, duration }\end{array}$ & 0.27 & 0.3 & 0.52 & 0.30 & 0.28 \\
$\begin{array}{l}\text { Random Forest, } \\
\text { duration }\end{array}$ & 0.25 & 0.4 & 0.47 & 0.37 & 0.42 \\
$\begin{array}{l}\text { SVM, large } \\
\text { feature set, }\end{array}$ & 0.23 & 0.42 & 0.38 & 0.38 & 0.4 \\
$\begin{array}{l}\text { duration } \\
\text { SVM, duration }\end{array}$ & $\mathbf{0 . 3 3}$ & $\mathbf{0 . 4 5}$ & $\mathbf{0 . 4 3}$ & $\mathbf{0 . 4 7}$ & $\mathbf{0 . 4 8}$ \\
$\begin{array}{l}\text { SVM } \\
\begin{array}{l}\text { SVM, z-norm, } \\
\text { duration }\end{array}\end{array}$ & 0.3 & 0.45 & 0.45 & 0.48 & 0.45 \\
\hline \hline
\end{tabular}

TABLE VI

THE $\Delta_{\text {COMPETENCE }}$ ERROR COMPONENT FOR THE FEMALE PATIENT AT FIVE TIME POINTS

\begin{tabular}{lcccccc}
\hline \hline \multicolumn{1}{c}{ Model } & Phase 0 & Phase 1 & Phase 2 & Phase 3 & Phase 4 & $\Delta_{\text {COMPETENCE }}$ \\
\hline $\begin{array}{l}\text { Human } \\
\text { judgment }\end{array}$ & $\mathbf{0}$ & $\mathbf{0}$ & $\mathbf{0}$ & $\mathbf{0}$ & $\mathbf{0}$ & $\mathbf{0}$ \\
$\begin{array}{l}\text { S MLP, } \\
\text { duration }\end{array}$ & -1 & -1 & 0 & -1 & -1 & 4 \\
$\begin{array}{l}\text { C4.5, } \\
\text { duration }\end{array}$ & -1 & 0 & 0 & 0 & 0 & 1 \\
$\begin{array}{l}\text { Random } \\
\begin{array}{l}\text { Forest, } \\
\text { duration }\end{array}\end{array}$ & -1 & 0 & 0 & -1 & -1 & 3 \\
$\begin{array}{l}\text { SVM, } \\
\text { large } \\
\begin{array}{l}\text { featureset, } \\
\text { duration }\end{array}\end{array}$ & -1 & 0 & 0 & 0 & 0 & 1 \\
$\begin{array}{l}\text { SVM, } \\
\text { duration }\end{array}$ & $\mathbf{- 1}$ & $\mathbf{0}$ & $\mathbf{0}$ & $\mathbf{0}$ & $\mathbf{0}$ & $\mathbf{1}$ \\
$\begin{array}{l}\text { SVM } \\
\text { SVM } \\
\text { z-norm, } \\
\text { duration }\end{array}$ & -1 & 0 & 0 & 0 & 0 & 1 \\
\hline \hline
\end{tabular}

TABLE VII

FREQUENCY OF CORRECTLY RECOGNISED SAMPLES FOR THE MALE PATIENT

\begin{tabular}{|c|c|c|c|c|c|}
\hline Model & Phase 0 & Phase 1 & Phase 2 & Phase 3 & Phase 4 \\
\hline $\begin{array}{l}\text { Human } \\
\text { judgments }\end{array}$ & 0.46 & 0.43 & 0.43 & 0.43 & 0.44 \\
\hline MLP, duration & 0.29 & 0.28 & 0.29 & 0.43 & 0.26 \\
\hline $\mathrm{C} 4.5$, duration & 0.26 & 0.23 & 0.26 & 0.27 & 0.28 \\
\hline $\begin{array}{l}\text { Random Forest, } \\
\text { duration }\end{array}$ & 0.31 & 0.3 & 0.28 & 0.28 & 0.33 \\
\hline $\begin{array}{l}\text { SVM, large } \\
\text { feature set, } \\
\text { duration }\end{array}$ & 0.25 & 0.3 & 0.25 & 0.38 & 0.3 \\
\hline SVM, duration & 0.26 & 0.28 & 0.34 & 0.35 & 0.28 \\
\hline SVM & 0.28 & 0.23 & 0.4 & 0.31 & 0.41 \\
\hline $\begin{array}{l}\text { SVM, z-norm, } \\
\text { duration }\end{array}$ & 0.31 & 0.35 & 0.34 & 0.4 & 0.39 \\
\hline
\end{tabular}

TABLE VIII

THE $\Delta_{\text {COMPETENCE }}$ ERROR COMPONENT FOR THE MALE PATIENT AT FIVE TIME POINTS.

\begin{tabular}{|c|c|c|c|c|c|c|}
\hline Model & Phase 0 & Phase 1 & Phase 2 & Phase 3 & Phase 4 & $\Delta_{\text {COMPETENCE }}$ \\
\hline $\begin{array}{l}\text { Human } \\
\text { judgments }\end{array}$ & 0 & 0 & $\mathbf{0}$ & 0 & 0 & 0 \\
\hline $\begin{array}{l}\text { MLP, } \\
\text { duration }\end{array}$ & 0 & 0 & 0 & 0 & 0 & 0 \\
\hline $\begin{array}{l}\text { C4.5, } \\
\text { duration }\end{array}$ & 0 & 0 & -1 & 0 & 0 & 1 \\
\hline $\begin{array}{l}\text { Random } \\
\text { Forest, } \\
\text { duration }\end{array}$ & 0 & 0 & 0 & 0 & 0 & 0 \\
\hline $\begin{array}{l}\text { SVM, large } \\
\text { featureset, } \\
\text { duration }\end{array}$ & 0 & 0 & 0 & 0 & 0 & 0 \\
\hline $\begin{array}{l}\text { SVM, } \\
\text { duration }\end{array}$ & 0 & $\mathbf{0}$ & $\mathbf{0}$ & 0 & 0 & 0 \\
\hline SVM & 0 & 0 & 0 & 0 & 0 & 0 \\
\hline $\begin{array}{l}\text { SVM } \\
\text { z-norm, } \\
\text { duration }\end{array}$ & 0 & 0 & 0 & 0 & 0 & 0 \\
\hline
\end{tabular}




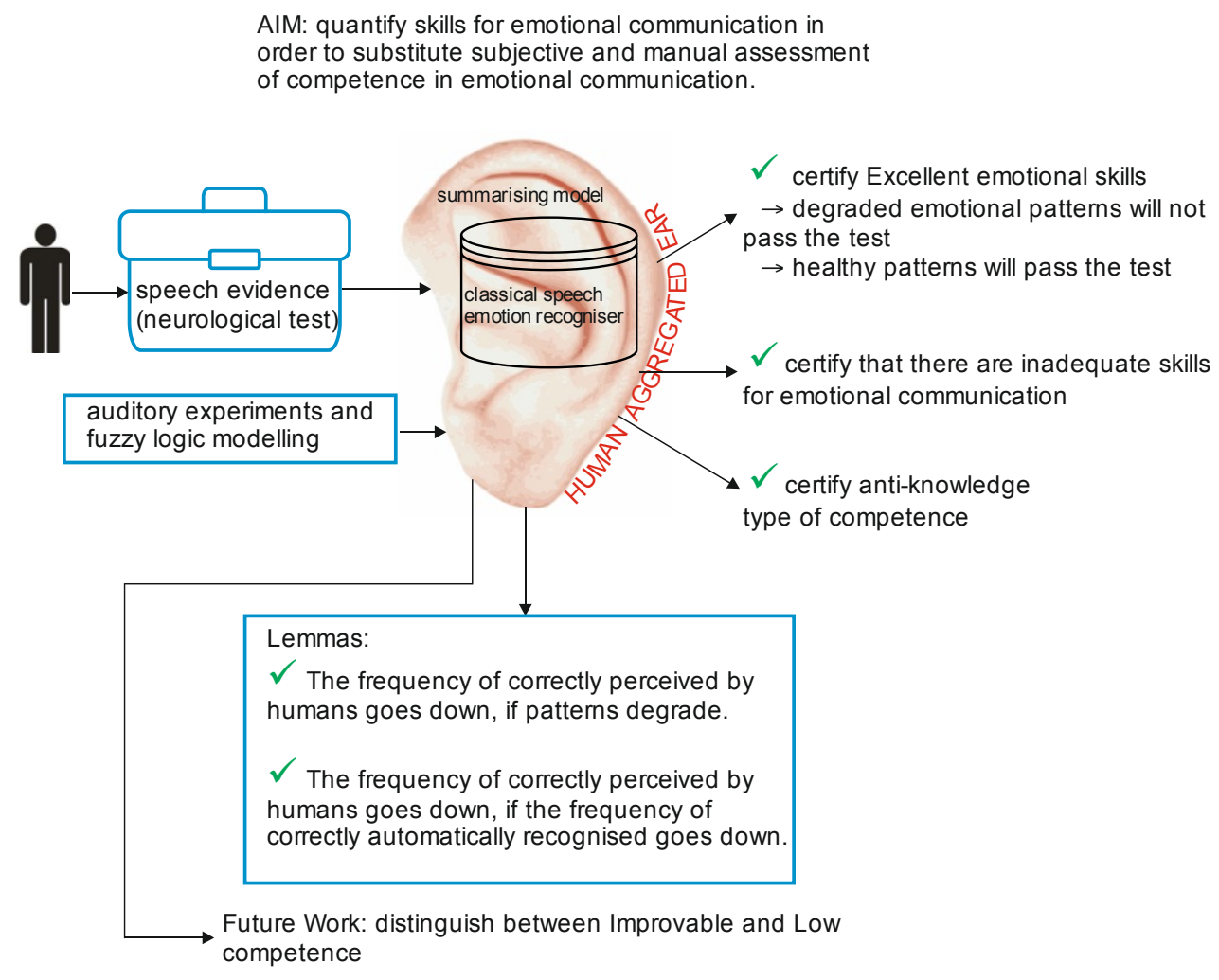

Fig. 6. Graphical conclusions of the study.

\section{DISCUSSION}

I. The size of the test set (99 samples of excellent quality) and a resulting wide confidence margin (8,5\%) bring up a possibility of an elevated number of false negatives and, threfore, motivates the following heuristic. Until the confidence margin is made smaller via making the test set bigger, take the UAR $=0,61$ as a threshold to conclude that emotional skills are excellent. The duration of the neurological test is recommended to be extended to 40 minutes (See Note in the Appendix).

II. The improvable and low competence bins overlap, which for our clinical data, allowed us to learn the values of the point of "maximal ambiguity" between competent and incompetent. There is no guarantee that this value will not change for a new portfolio. Presently, this is the limit of the disease-independent approach. The concrete values for the point of maximal ambiguity from this study can be used as a reference point in assessing new portfolios. For future work, in order to approximate the point of maximal ambiguity, a data-driven approach needs to be undertaken. In such an experiment, a separate portfolio of evidence becomes a data point, and a great deal more portfolios on patients with FAS are needed (which is hard to get) or portfolios on patients with distinct neurological diseases that are characterized with sufficiently distinct manifestations of pathology in emotional speech.

III. Neuroimaging study on the patients involved in the present study is outside the scope of the present paper. This type of analysis has been carried in one patient at baseline [25], and further account will be given in [43], where the impact of treatments in brain function in both patients and healthy subjects will be described, and the lesions caused by FAS (volume, location and the white matter pathways damaged) will be identified based on structural MRI.

\section{CONCLUSIONS}

At our departure point we ventured the automation in the situation under rather restrictive circumstances: a rare disorder with few patients and little data available. Moreover, according to its phonetic description in the medical literature, it affects the emotive speech heterogeneously, that is, with different acoustic parameters affected from patient to patient.

I. To quantify the communicative damage at a paralinguistic level caused by pathology, we have proposed four disjoint competence bins with tangible communicative consequences: excellent paralinguistic competence, improvable competence with successes in half of cases, low competence with failures in more than half of cases, and anti-knowledge (a will to do badly on the test or wrong patterns in the generative model). 
II. We have shown that using a predictive model trained on healthy emotive speech in the same language, it is possible to certify that a portfolio of speech evidence contains emotive speech of excellent competence (UAR is $61 \%$ ), and when anti-knowledge is involved (UAR is below the chance level). Insufficient competence (Improvable and Low) is certified via the exclusion of the Excellent and Anti-knowledge. It follows from the properties of the 4-class classification task with a known upper bound for UAR, and no assumptions are made about the pathology manifestation, distributions in the pathological speech or the number of patients.

III. The resulting system creates a "summary" of the evidence that contains the recordings of a reading-based neurological check-up. Therefore, the machine can provide decision support to a speech therapist.

The conclusions are summarized in Figure 6.

\section{ACKNOWLEDGMENT}

This work is part of the research project "Scalable resourceefficient systems for big data analytics" funded by the Knowledge Foundation (grant: 20140032) in Sweden. The experiments were carried out at the infrastructure provided by HPI Future SOC Lab, Potsdam, Germany. We are thankful to Asunción Moreno for letting us use the Spanish part of the INTERFACE corpus. We thank Lars Lundberg and Claes Jogreus for letting their brain machinery for running our ideas. Last but not least, we wish to express our gratitude to the editor and the anonymous reviewers.

\section{REFERENCES}

[1] W. Colburn, V.G. DeGruttola, D.L. DeMets, G.J. Downing, D.F. Hoth, J.A. Oates, C.C. Peck, R.T. Schooley, B.A. Spilker, J. Woodcock, S.L. Zeger, "Biomarkers and surrogate endpoints: Preferred definitions and conceptual framework. Biomarkers Definitions Working Group." Clinical Pharmacol \& Therapeutics, vol. 69, no. 3, pp. 89-95, 2001.

[2] A. House, D. Rowe, P.J. Standen, "Affective prosody in the reading voice of stroke patients", Journal of Neurology, Neurosurgery \& Psychiatry, vol. 50, no. 7, pp. 910-912, 1987.

[3] S. Ahmed, A.M.F. Haigh, C.A de Jager, P. Garrard, "Connected speech as a marker of disease progression in autopsy-proven Alzheimer's disease", Brain, vol. 136, no. 12, pp. 3727-3737, 2013.

[4] J. Van Santen, E. Prud'Hommeaux, L. M. Black, M. Mitchell, "Computational prosodic markers for autism", Autism, vol. 14, no. 3, pp. 215-236, 2010.

[5] M. Lehr, E. Prud'hommeaux, I. Shafran, B. Roark, "Fully automated neuropsychological assessment for detecting mild cognitive impairment", in Interspeech, Portland, USA, 2012, pp. 1039--1042.

[6] J. R. Orozco-Arroyave, F. Hönig, J. D. Arias-Londoño, J. F. Vargas-Bonilla, K. Daqrouq, S. Skodda, ... ,E. Nöth, "Automatic detection of Parkinson's disease in running speech spoken in three different languages", Journal of the Acoustical Society of America, vol. 139, no. 1, pp. 481-500, 2016.

[7] A. Tversky, 1969, "Intransitivity of Preferences", in Preference, Belief, and Similarity, E. Shafir ed.,
Cambridge, Massachusetts, USA, MIT press, 2004, ch. 19, pp. 433-463.

[8] T. Hastie, R. Tibshirani, "Classification by Pairwise Coupling", The Annals of Statistics, vol. 26, no. 2, pp. 451-471, 1998.

[9] C. Fourali, "Using fuzzy logic in educational measurement: the case of portfolio assessment", Evaluation and Research in Education, vol. 11, no. 3, pp. 129-148, 1997.

[10] B. Schuller, B. Vlasenko, F. Eyben, M. Wollmer, A. Stuhlsatz, A. Wendemuth, G. Rigoll, "Cross-corpus acoustic emotion recognition: Variances and strategies", IEEE Transactions on Affective Computing, vol. 1, no. 2, pp. 119-131, 2010.

[11] A. Muaremi, B. Arnrich, G. Tröster, "Towards measuring stress with smartphones and wearable devices during workday and sleep", BioNanoScience, vol. 3, no. 2, pp. 172-183, 2013.

[12] M.Van Segbroeck, R. Travadi, C. Vaz, J.Kim, M. P. Black, A. Potamianos, S. Narayanan, "Classification of cognitive load from speech using an i-vector framework", in Interspeech, Singapore, 2014, pp. 751-755.

[13] A. C. Aguiar, M. Kaiseler, H. Meinedo, T. E. Abrudan, P. R. Almeida, "Speech stress assessment using physiological and psychological measures", in Ubicomp, Zurich, Switzerland, 2013, pp. 921--930.

[14] M. Li, "Automatic recognition of speaker physical load using posterior probability based features from acoustic and phonetic tokens", in Interspeech, Singapore, 2014, pp. 437--441.

[15] D. Bone, C. Lee, S. Narayanan, "Robust unsupervised arousal rating: A rule-based framework with knowledgeinspired vocal features", IEEE transactions on affective computing, vol. 5, no. 2, pp. 201-213, 2014.

[16] O. Räsänen, J. Pohjalainen, "Random subset feature selection in automatic recognition of developmental disorders, affective states, and level of conflict from speech", in Interspeech, Lyon, France, 2013, pp. 210-214.

[17] D. Bone, T. Chaspari, K. Audhkhasi, J. Gibson, A. Tsiartas, M. Van Segbroeck, ..., S. Narayanan, "Classifying language-related developmental disorders from speech cues: the promise and the potential confounds", in Interspeech, Lyon, France, 2013, pp. $182--186$

[18] A. Bayestehtashk, M. Asgari, I. Shafran, J. McNames, "Fully automated assessment of the severity of Parkinson's disease from speech", Computer speech \& language, vol. 29, no. 1, pp. 172-185, 2015.

[19] T. Bocklet, S. Steidl, E. Nöth, S. Skodda, "Automatic evaluation of Parkinson's speech-acoustic, prosodic and voice related cues", in Interspeech, Lyon, France, 2013, pp. 1149-1153.

[20] J. Kim, M. Nasir, R. Gupta, M. Van Segbroeck, D. Bone, M. P. Black, S. Narayanan, S., "Automatic estimation of parkinson's disease severity from diverse speech tasks", in Interspeech, Dresden, Germany, 2015, pp. $914-918$.

[21] K. Lopez-de-Ipiña, J.B. Alonso, J. Solé-Casals, N. Barroso, P. Henriquez, M. Faundez-Zanuy, C.M. Travieso, M. Ecay-Torres, P. Martinez-Lage, H. Eguiraun, "On automatic diagnosis of Alzheimer's disease based on spontaneous speech analysis and emotional temperature", Cognitive Computation, vol. 7, no. 1, pp. 44-55, 2015.

[22] R. Gajšek, F. Mihelic, S. Dobrišek, "Speaker state recognition using an HMM-based feature extraction method", Computer Speech \& Language, vol. 27, no. 1, pp. 135-150, 2013.

[23] D. Suendermann-Oeft, V. Ramanarayanan, M. Teckenbrock, F. Neutatz, D. Schmidt. "HALEF: An 
Open-Source Standard-Compliant Telephony-Based Modular Spoken Dialog System: A Review and An Outlook", in Natural Language Dialog Systems and Intelligent Assistants, G. Geunbae Lee, H. Kook Kim, M. Jeong, J.-H. Kim (eds.), Springer International Publishing, 2015, ch. 5, pp. 53-61.

[24] C. L. Huang, Y. Tsao, C. Hori, H. Kashioka, "Feature normalization and selection for robust speaker state recognition", in COCOSDA, Hsinchu, Taiwan, 2011, pp. $102-105$

[25] I. Moreno-Torres, M. L. Berthier, M. del Mar Cid, C. Green, A. Gutiérrez, N. García-Casares, ... C. CarneroPardo, "Foreign accent syndrome: a multimodal evaluation in the search of neuroscience-driven treatments", Neuropsychologia, vol. 51, no. 3, pp. 520-537, 2013.

[26] V. Hozjan, Z. Kacic, A. Moreno, A. Bonafonte, A. Nogueiras, "Interface Databases: Design and Collection of a Multilingual Emotional Speech Database", in LREC, Las Palmas, Spain, 2002, pp. 2024 -- 2028.

[27] I. S. Engberg, A. V. Hansen, O. Andersen, P. Dalsgaard, "Design, recording and verification of a Danish emotional speech database", in Eurospeech, Rhodes, Greece, 1997, pp. 1695--1698.

[28] L. A. Zadeh, "Fuzzy Logic and Beyond - A New Look", in Fuzzy Sets and their applications to cognitive and decision processes: Proceedings of the US-Japan seminar on fuzzy sets and their applications, L. Zadeh, F. King-Sun, T. Konichi (eds.), New York, USA, Academic Press, 2014, ch. 1, pp: 1-4.

[29] L.A. Zadeh, "Fuzzy sets", Inform. And control, vol. 8, no. 3, pp. 338-353, 1965.

[30] T. Bilgiç, I. B. Türkşen. Measurement of membership functions: theoretical and empirical work. In Fundamentals of fuzzy sets, D. Dubois, H. Prade (ed.), Boston, MA, USA, Springer, 2000, ch. 3, pp. 195-227.

[31] D. N. Osherson, E. E. Smith, "On the adequacy of prototype theory as a theory of concepts", Cognition vol. 9 , no. 1 , pp. $35-58,1981$.

[32] D. N. Osherson, E. E. Smith. Gradedness and conceptual combination, Cognition 12: pp. 299-318, 1982.

[33] J. Sidorova, "Speech emotion recognition", UPF, Barcelona, Spain, 2007.

[34] J. Sidorova, T. Badia, "ESEDA: A Tool for Enhanced Speech Emotion Detection and Analysis", in AXMEDIS, Florence, Italy, 2008, pp. 257--260.

[35] J. Sidorova, "Optimization techniques for speech emotion recognition", Ph.D. dissertation, Dept. Trad. i Filol., UPF, Barcelona, Spain, 2009.

[36] F. Eyben, M. Wöllmer, B. Schuller, "Opensmile: the munich versatile and fast open-source audio feature extractor", in MM, Firenze, Italy, 2010, pp. 1459--1462.

[37] F. Eyben, M. Wöllmer, F. Gross, B. Schuller, "Recent developments in opensmile, the munich open-source multimedia feature extractor", in MM' 13, Barcelona, Spain, 2013, pp. 835--838.

[38] M. A. Hall, "Correlation-based Feature Selection for Machine Learning". Ph.D dissertation, Dept. of Computer Science, Waikato Univ., New Zealand, 1998.

[39] E. Frank, M. Hall, G. Holmes, R. Kirkby, B. Pfahringer, I. Witten, "WEKA: A machine learning workbench for data mining", in Data mining and knowledge discovery handbook, O. Maimon \& L. Rokach (eds.), US, Springer, 2005 , pp. 1265-1277.

[40] T. Mitchell, "Evaluating Hypotheses", in Machine Learning, McGrow-Hill T. Mitchell, McGraw Hill, ch. 5, pp. 128-152, 1997.

[41] I. Iriondo, S. Planet, JC. Socoro, E. Martinez, F. Alias, C. Monzo, "Automatic refinement of an expressive speech corpus assembling subjective perception and automatic classification", Speech Communication, vol. 50, no. 5, pp. 416-433, 2008.
[42] G. W. Corder, D.I. Foreman, "Nonparametric statistics for non-statisticians: A step-by-step approach", New York: Wiley, 2009.

[43] Berthier, M.L. Moreno-Torres, I., Roé-Vellvé, N. Thurnhofer, K., Sidorova, J. Foreign accent syndrome treatment (FAST). Remodelling of cortico-subcortical loops with audiovisual neurofeedback and cholinergic enhancement. (in preparation).

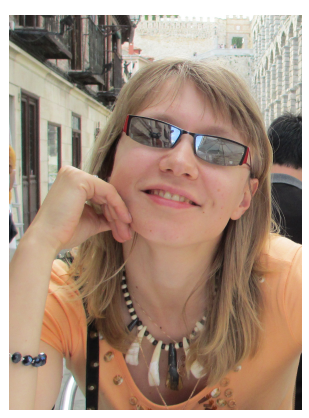

J. Sidorova was born in Moscow, USSR in 1980. She received the M.S. degrees in linguistics from Moscow State University, in 2002 and the Ph.D. degree in cognitive sciences from Universitat Pompeu Fabra, Barcelona, in 2010.

From 2010 to 2014, she was a postdoctoral fellow at Universitat Autonoma de Barcelona and Universidad Carlos III de Madrid, Spain. Since 2015, she has been with Blekinge Institute of Technology, where she is an Assistant Professor with the Department of Computer Science. She is the author of 26 scientific articles with the research interests including pattern recognition, knowledge discovery, cognitive paralinguistics and innovation biomedical applications.

S. Karlsson is studying towards MS in Computer Science at Blekinge Institute of Technology. In summer 2015, he was a research intern at the same department. His research interests include machine learning and data analytics.

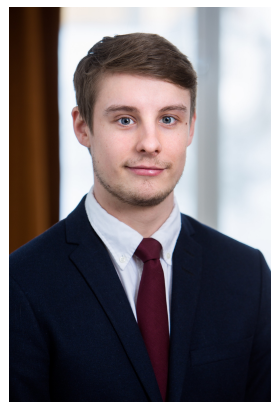

O. Rosander is studying towards MS in Computer Science at Blekinge Institute of Technology. From 2015 to 2018 , he was a research assistant at the same department and co-authored several published articles regarding applied data analytics. His research interests include machine learning and data analytics.

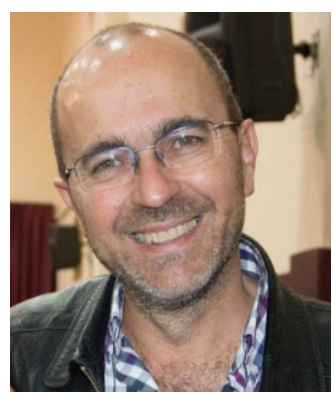

I. Moreno-Torres was born in Jaen Spain in 1965. He received a M.S. degree in Philology from University of Málaga, Spain, in 1988, and the Ph.D. degree in Spanish Language from the Universitat Autonoma de Barcelona in 1994.

Since 1998 his has been an Associate Professor at the Spanish Language Department, 
Universidad de Málaga. He is the author of three books and more than 30 articles. His research interests include speech and language development in typical children and in children with Cochlear implants. Recently he has become interested in the area of speech perception in noise.

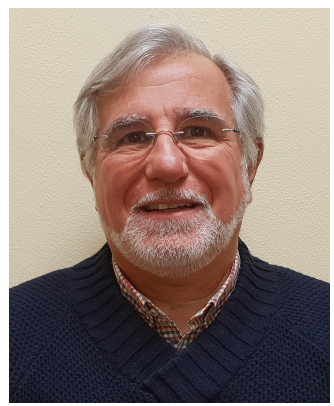

M. Berthier received a M.S. degree in Medicine from University of Buenos Aires and the M.D. degree in Neuroscience from the University of Malaga in 2000.

Currently he is a professor of Neurology at the Department of Medicine, University of Malaga, and Director of the Unit of Cognitive Neurology (UNCA) and Aphasia at the Centro de Investigaciones Médico-Sanitarias (CIMES), UMA. He is a recipient of a prestigious national award for Alzheimer's research (2011) from the Spanish Society for Neurology. 